\title{
LA COOPERACIÓN INTERMUNICIPAL COMO ESTRATEGIA DE ORDENACIÓN Y DESARROLLO TERRITORIAL EN ESPACIOS TRANSFRONTERIZOS: LAAGRUPACIÓN EUROPEA DE COOPERACIÓN TERRITORIAL DUERO-DOURO'
}

\author{
Fernando Manero Miguel \\ Departamento de Geografía y Ordenación del Territorio. Universidad de Valladolid
}

\section{RESUMEN}

Si la cooperación intermunicipal constituye una de las modalidades de actuación de mayor trascendencia para la ordenación sostenible y equilibrada del territorio, es evidente que sus líneas de actuación y su nivel de eficacia se enfrentan a desafíos importantes cuando las relaciones se plantean en el contexto de los espacios transfronterizos. La creación en 2006 de las Agrupaciones Europeas de Cooperación Territorial, una figura comunitaria específicamente aplicada a la cooperación territorial, introduce una nueva perspectiva de indudable interés estratégico, que cobra dimensión explícita, a través de la denominada Duero-Douro, en un sector crítico de la frontera hispano-portuguesa.

Palabras claves: Cooperación intermunicipal, Espacios transfronterizos, Política de Cohesión, Agrupaciones Europeas de Coooperación Territorial, Desarrollo Rural, Geografía del Derecho

Fecha de recepción: septiembre 2010.

Fecha de aceptación: febrero 2012.

1 La realización de este trabajo se inscribe en la línea de investigación amparada en el Proyecto «Nuevas metodologías y directrices aplicadas a la ordenación y gestión del territorio: estudio comparado de las políticas territoriales de Castilla y León en el contexto español e internacional»(VA025A08). 


\section{ABSTRACT}

Inter-municipal cooperation is one of the most important options for sustainable and balanced territorial planning and its lines of approach and level of effectiveness evidently face significant challenges when relations correspond to cross-border areas. The creation of the European Groupings of Territorial Corporation in 2006 as a Community concept specifically applied to territorial cooperation brings in a new perspective of unquestionable strategic interest and one that takes on particular relevance through the so-called DueroDouro along a critical sector of the Spanish-Portuguese border.

Key words: Intermunicipal Cooperation, Cross-border Areas, Cohesion Policy, European Grouping Territorial Cooperation, Rural Development, Legal Geography.

\section{INTRODUCCIÓN}

Las políticas de reestructuración social, económica y cultural aplicadas a los espacios transfronterizos siempre han representado uno de los principales desafíos en las directrices de ordenación del territorio y desarrollo regional, en función de las particularidades que derivan de la cooperación estratégica entre administraciones públicas vinculadas a Estados, $\mathrm{y}$, por tanto, a normativas reguladoras distintas, que a la par se corresponden con identidades culturales bien marcadas en cada caso (Wilson \& Donnan, 1998:5). Desde que en 1980 el Consejo de Europa insistiera en la singularidad de los espacios de frontera como una cuestión de relevancia específica y primordial para la comprensión integrada del espacio europeo, todo un proceso de maduración, tanto desde la perspectiva teórica como práctica, se ha llevado a cabo hasta hacer de la cooperación transfronteriza una de las piezas maestras en el proceso de asimilación de las posibilidades que emanan del compromiso entre territorios políticamente diferenciados, lo que a su vez se corresponde con la atención creciente concedida a este hecho político-espacial como un factor clave en el proceso de construcción del espacio europeo integrado (O’Dowd, 2002:15; Anderson \& alii, 2003: 3).

En esta premisa se asienta la idea central surgida del Convenio Marco Europeo sobre cooperación transfronteriza, firmado en Madrid el 21 de mayo de 1980 - y posteriormente desarrollado en el Protocolo Adicional de 9 de noviembre de 1995 - con la voluntad de alentar la colaboración entre autoridades territoriales. Desde entonces, muchas y diversas han sido las manifestaciones que ponen al descubierto la multiplicidad de facetas de que es susceptible esta estrategia de desarrollo, plasmada en un interesante panorama de experiencias donde confluyen al tiempo los resultados conseguidos y los obstáculos que los mediatizan, vistos en ambos casos desde la valoración que proporciona un horizonte temporal significativo.

Sin necesidad de entrar en una consideración pormenorizada de sus ambivalencias, y de las que da cuenta sobrada la abundante bibliografía sobre la cuestión, interesa destacar el margen de posibilidades abiertas bajo las coordenadas del nuevo marco de relaciones propiciado por un instrumento que ve la luz en 2006 - las Agrupaciones Europeas de Cooperación Territorial - en la medida en que introducen un drástico e importante cambio de enfoque respecto a las pautas de funcionamiento anteriores. Y, aunque la perspectiva aún 
disponible sobre su nivel de efectividad no sea suficientemente dilatada en el tiempo, resulta de interés la toma en consideración, y con un enfoque prospectivo, de las actuaciones que tratan de ampararse en las posibilidades de esta figura en áreas donde los esfuerzos por afianzar los vínculos fraguados en torno a la frontera gozan de una trayectoria tan enraizada como asumida por quienes en el territorio contemplan las interrelaciones a ambos lados como una opción que conviene respaldar al entender que abre horizontes y sinergias que de otro modo serían imposibles o, en cualquier caso, se verían seriamente cercenados.

Es además una cuestión que conviene analizar teniendo en cuenta la importancia que, a mi juicio, debe otorgarse a la interpretación con criterios espaciales de las normas jurídicas aplicadas a la ordenación y gobierno del territorio, y sobre la que cabe esperar avances de gran utilidad operativa a partir del tratamiento y valoración de las imbricaciones que entrelazan la Geografía y el Derecho, lo que justificadamente ha llevado a hablar de las relevantes posibilidades metodológicas e interpretativas asociadas a una «Geografía Jurídica» (Cavaillé, 2009:59 y ss).

\section{LOS GRANDES DESAFÍOS DE LA COOPERACIÓN TRANSFRONTERIZA: POSIBILIDADES Y CONDICIONAMIENTOS}

Esta modalidad de cooperación orientada al desarrollo regional, sobre la base del aumento de la permeabilidad entre espacios diferenciados y a la vez contiguos, constituye la expresión más palmaria de un propósito decidido a favor de la superación de las rupturas ocasionadas en el territorio por la discontinuidad política, jurídica y cultural que establece la frontera, por más que deba ser entendida «no exclusivamente como una línea divisoria, sino también como un lugar de comunicación» (Jácomo, 2005, 233), en el que confluyen numerosas funciones que se complementan y enriquecen entre sí (Raffestin, 1993, 158). Representa, en efecto, un empeño resuelto y encomiable, que a lo largo del tiempo se ha reflejado en la puesta en práctica de instrumentos adaptados a la voluntad de encuentro y recomposición de los vínculos por parte de las instituciones de los Estados implicados, de acuerdo con las premisas marcadas por el Convenio Marco Europeo sobre cooperación transfronteriza ya señalado.

Firmado finalmente por España el 1 de octubre de 1986, y posteriormente ratificado el 10 de julio de 1990, su aplicación cobrará carta de naturaleza a raíz de los Tratados de cooperación bilateral concertados con Francia (en Bayona) el 10 de marzo de 1995 y con Portugal (en Valencia) el 3 de octubre de $2002^{2}$. Uno y otro definen la cobertura legal en la que se apoya la adopción de este tipo de estrategias por parte de las administraciones subestatales (Comunidades Autónomas y Entidades Locales) con voluntad para llevarlas a cabo a partir de convenios internacionales destinados a la creación de organismos específicos de cooperación con o sin personalidad jurídica ${ }^{3}$. Organismos cuya operatividad es indisociable

2 Su entrada en vigor tendrá lugar el 24 de febrero de 1997 y el 30 de marzo de 2004, respectivamente.

3 En la relación con Portugal se trata de las Comunidades de Trabajo y de los Grupos de Trabajo para los organismos sin personalidad jurídica, y de las Asociaciones de Derecho Público y Empresas Intermunicipales (Portugal) y los Consorcios (España), en el caso de los organismos con personalidad jurídica. De que la tengan o no depende la capacidad funcional de dichas entidades. De ahí que, cuando se ha abordado la gestión en común de equipamientos o servicios públicos, o de la realización de actuaciones cubiertas por los Programas de la iniciativa comunitaria INTERREG ha sido necesario crear organismos con personalidad jurídica. 


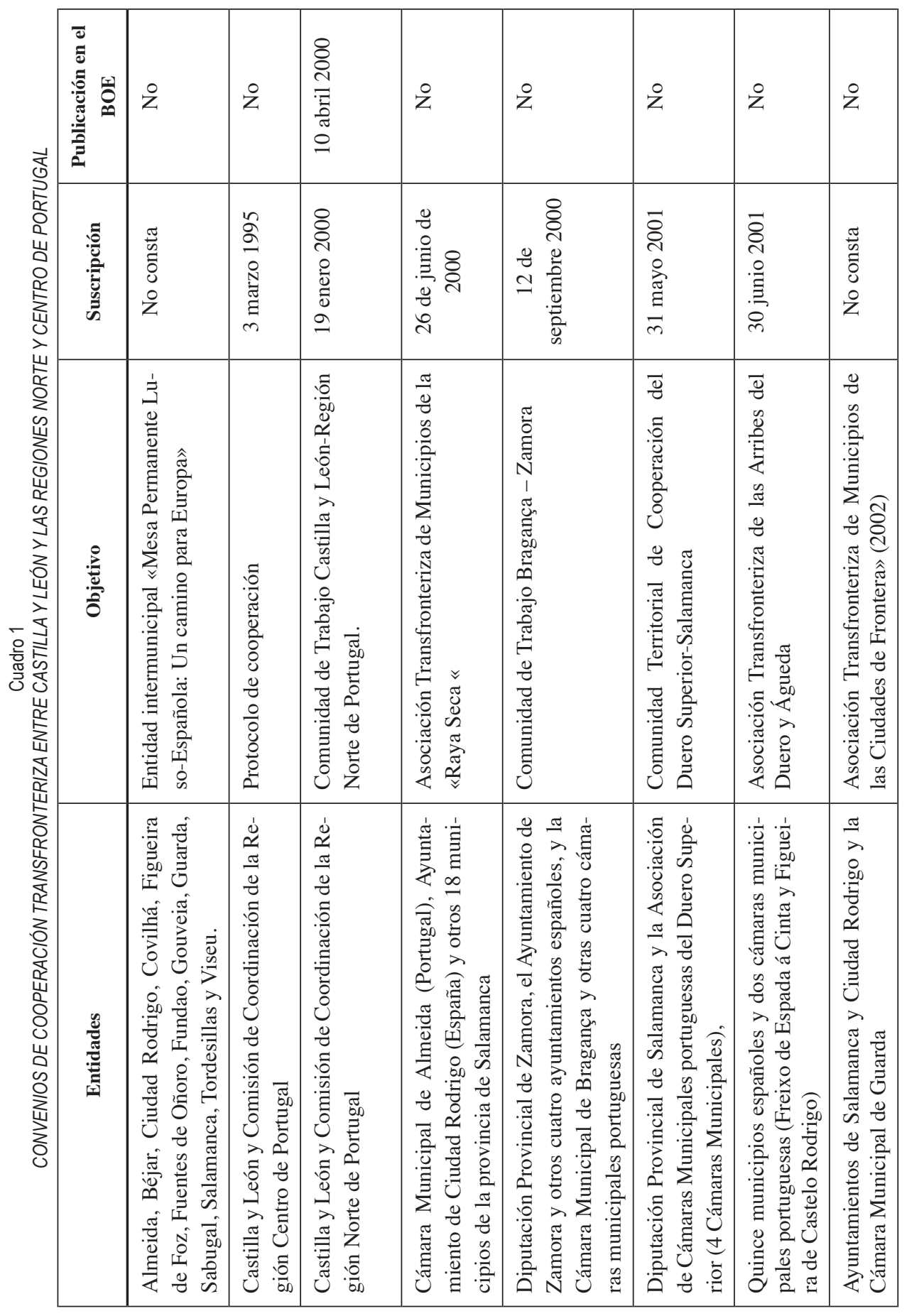




\begin{tabular}{|c|c|c|c|c|c|c|}
\hline 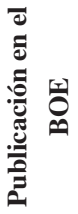 & $\stackrel{\circ}{z}$ & 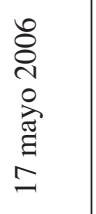 & 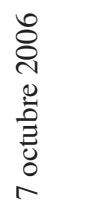 & $\stackrel{\circ}{z}$ & 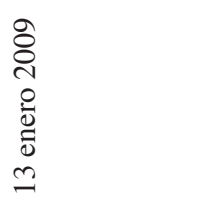 & 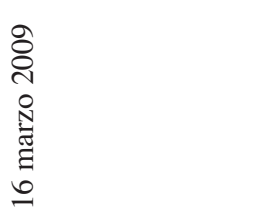 \\
\hline 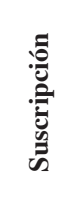 & $\begin{array}{l}\tilde{J} \\
\tilde{0} \\
\tilde{0} \\
0 \\
\dot{Z}\end{array}$ & 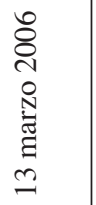 & 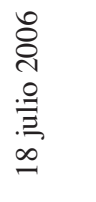 & 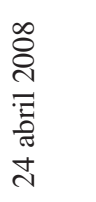 & 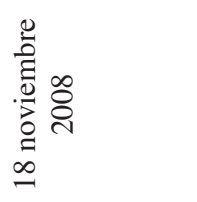 & $\begin{array}{l}\text { ठे } \\
\text { ते } \\
\dot{\Xi} \\
\tilde{0} \\
\hat{N}\end{array}$ \\
\hline$\frac{\stackrel{2}{0}}{\frac{1}{0}}$ & 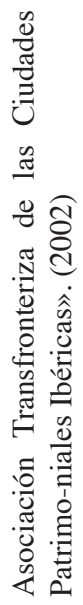 & 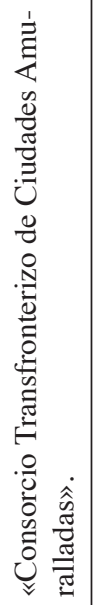 & 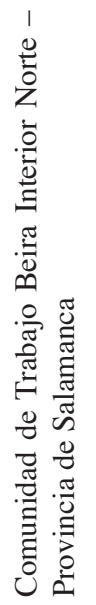 & 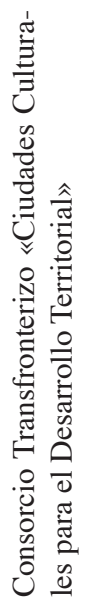 & 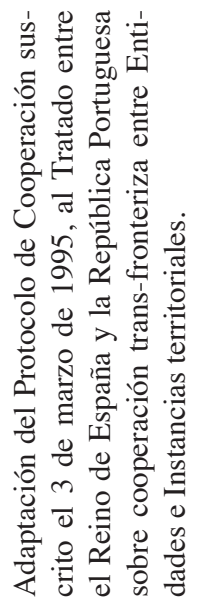 & 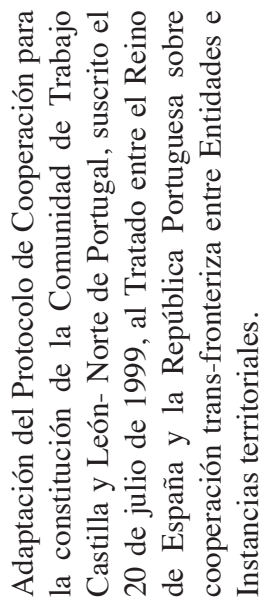 \\
\hline 承 & 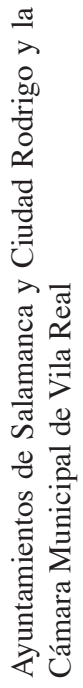 & 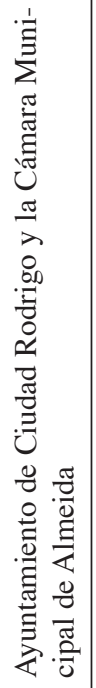 & 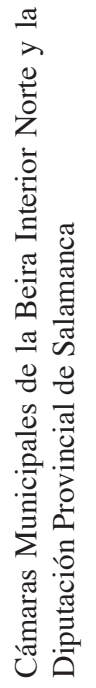 & 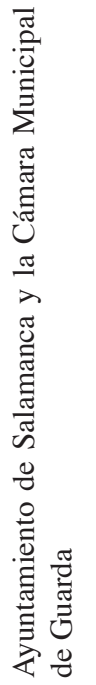 & 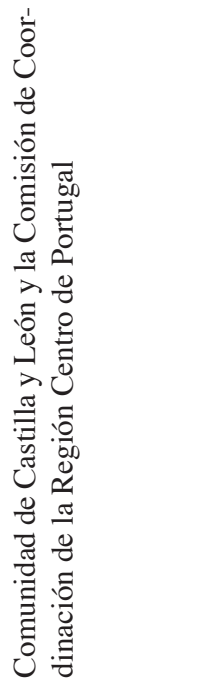 & 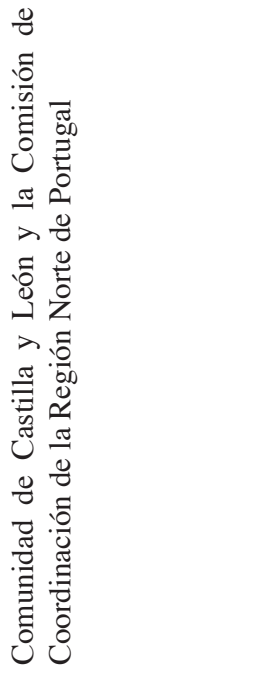 \\
\hline
\end{tabular}

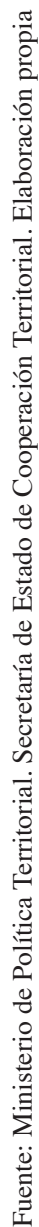


del procedimiento de información al que han de sujetarse, tal y como se contempla en el Real Decreto 1317/1997, de 1 de agosto (BOE de 29 de agosto), sobre comunicación previa a la Administración General del Estado y publicación oficial de los convenios de cooperación transfronteriza de regiones y municipios con entidades territoriales extranjeras ${ }^{4}$.

Si el planteamiento inicial de referencia impulsado por el Consejo de Europa abrió camino a la formalización de las relaciones cooperativas entre Estados, el gran paso adelante, con visos de lograr una voluntad efectiva en esta línea, consistirá en el respaldo proporcionado por la política de desarrollo regional de la Comisión a través de las Iniciativas Comunitarias y, en particular, de la concebida ex profeso con este fin, y que bien puede ser considerada como uno de los mecanismos de mayor significación territorial desde los inicios de la integración de España en las Comunidades Europeas (Manero y Pastor, 1986, 49). Concebida con el propósito de favorecer la adaptación de las áreas fronterizas a las lógicas económico-territoriales del espacio funcionalmente integrado, la puesta en marcha de INTERREG en el periodo 19891993 introdujo una línea de actuación muy sensible con las particularidades de este tipo de escenarios, para mantener a lo largo de su trayectoria una clara coherencia con sus objetivos iniciales. Así ocurrirá en el período siguiente (1994-1999), cuando a la dimensión transfronteriza de sus actuaciones se sume la relacionada con la articulación transnacional de las redes de electricidad y gas natural, para incorporar a partir de 1996 un nuevo epígrafe estratégico, orientado al fomento de la cooperación a gran escala, que continuaría en la etapa 2000-2006, en la que INTERREG amplia su perspectiva como cooperación transeuropea, estructurada en tres líneas - transfronteriza (A), transnacional (B) e interregional (C) - de las que la primera será con creces la que reciba el volumen de dotación más relevante.

El ámbito identificado con el tramo de la raya que separa a Castilla y León de las Regiones Norte y Centro de Portugal representa un expresivo escenario de intervención cuando se trata de valorar la importancia de las iniciativas de cooperación promovidas al efecto, el nivel de participación alcanzado y su difusión en el espacio, por cuanto «hablar de raya fronteriza entre Portugal y España es hablar de una realidad muy específica de las relaciones entre los dos países» (Jácomo, 2005:247), habida cuenta además de que sirve para entender de forma palmaria la urdimbre de intercambios, no exentos de conflicto, que a lo largo del tiempo se han ido fraguando entre «iberismo y cooperación» (Cabero, 2002).

Mas no se trata en este artículo de hacer una valoración del balance obtenido sino de las manifestaciones que lo han hecho posible sobre la base de los instrumentos de cooperación aplicados, como expresión del engarce que se produce entre las posibilidades creadas por los acuerdos bilaterales y las intervenciones auspiciadas por los Fondos Estructurales canalizados a través de los sucesivos INTERREG. Importa, ante todo, destacar el abanico de opciones que a lo largo del tiempo se han plasmado en convenios de cooperación, en los que

4 Se aprueba el Real Decreto 1317/1997, de 1 de agosto (BOE de 29 de agosto), sobre comunicación previa a la Administración General del Estado y publicación oficial de los convenios de cooperación transfronteriza de Comunidades Autónomas y Entidades Locales con Entidades Territoriales extranjeras. En el caso de las Comunidades Autónomas, han de atenerse a lo establecido en lo previsto en el Acuerdo de la Conferencia para Asuntos Relacionados con las Comunidades Europeas de 2 de diciembre de 1996 (BOE de 12 de diciembre de 1997), mientras las Entidades Locales se ajustan al Acuerdo de la Comisión Nacional de Administración Local de 30 de enero de 1997 (BOE de 12 de diciembre de 1997). En ambos casos se precisa el procedimiento para cumplir lo establecido en el Real Decreto 1317/1997. 
los Ayuntamientos y las Cámaras Municipales han tenido un protagonismo incuestionable, como puede verse en el cuadro 1.

Si esta desagregación de iniciativas, ordenadas en el tiempo, nos sitúa ante un panorama tan expresivo como interesante, en la medida en que permite valorar la pluralidad de agentes que intervienen, es obvio que a la par pone al descubierto resultados muy variables en función de la desigual trayectoria y balance variable que unas y otras experiencias ofrecen. Como puede verse, son numerosos los convenios que no han adquirido plasmación legal a través de su publicación en el Boletín Oficial del Estado, lo que les priva de «efectos jurídicos en España frente a sujetos distintos de las entidades territoriales firmantes» al no cumplir lo establecido en el Art. 2 del Real Decreto 1317/1997, donde explícitamente se indica la obligatoriedad de esta publicación ${ }^{5}$.

Con todo, y al margen de su evolución ulterior, no cabe duda de que tanto en la intencionalidad de dichos convenios, concebidos para la creación de una estructura de colaboración permanente, como a través de las actuaciones que los acompañan anida el propósito firme de abrir nuevos horizontes al desarrollo de los intercambios previstos, de estimular el conocimiento mutuo, de acometer la valorización de recursos compartidos, de favorecer «un mejor entendimiento entre las autoridades públicas y las organización privadas y semipúblicas a uno y otro lado de la frontera», según subraya la Comisión Europea en el Tercer Informe sobre la Cohesión Económica y Social (TICES) $(2004,20)$ y, por supuesto, de impulsar programas y actuaciones que, al socaire del amparo proporcionado por INTERREG, han logrado adquirir una incidencia territorial explícita o bien «resolver problemas específicos que no podrían haberse resuelto mediante otros programas de ayuda» (Ibidem, 2004, 157).

Pero también es evidente que la cuestión central que atañe a los efectos derivados de la cooperación transfronteriza tiene mucho que ver con su continuidad, con el afianzamiento de su perspectiva a medio y largo plazo y con la sensación de equilibrio, equidad y atención de que puedan ser objeto a ambos lados de la raya. De ahí esa visión crítica que necesariamente emerge cuando se contempla la cuestionada eficacia de su alcance como estrategia de desarrollo susceptible de consolidación garantizada frente a los condicionamientos que entorpecen dicha finalidad.

Las consideraciones planteadas en esta dirección son insistentes en un argumento esencial, que adquiere fuerza y capacidad de convicción cuando se refiere a las dificultades a que se enfrentan las diferentes modalidades de cooperación planteadas entre Estados. En estos términos se manifestó, en efecto, el propio Consejo de Europa en 2002, a través de su Comisión de Expertos en Cooperación Transfronteriza, al recoger los argumentos planteados desde Portugal y España, en los que se observan coincidencias claras en relación con los contrastes desde el punto de vista administrativo, la disparidad de las respectivas legislaciones o la inadecuación de las infraestructuras existentes ${ }^{6}$. Y a su vez son consideraciones que tam-

5 Requisito reforzado a través de la Disposición Transitoria Única donde se indica que para asegurar «la adaptación a los Tratados Internacionales celebrados por el Reino de España para la aplicación del Convenio Marco Europeo, lo establecido en el presente Real decreto sobre publicación oficial será aplicable a los convenios de cooperación transfronteriza suscritos antes de su entrada en vigor».

6 COMMITEE OF EXPERTS ON TRANSFRONTIER CO-OPERATION): Report on the current state of the administrative and legal framework of transfrontier co-operation in Europe (2002), DGI- Legal Affairs, Council of Europe, Estrasburgo, 2002, p. 75 y p. 85. (Cit. por Merchán, 2003, 719). 
bién hacen acto de presencia en un documento de tanta trascendencia como el TICES, al que ya se ha aludido y que de manera contundente, y sobre la base del balance logrado, llega a la conclusión de que «el problema fundamental de la gestión de los programas transfronterizos y transnacionales son las normas legales y administrativas y las tradiciones, a menudo muy distintas, de los diferentes países involucrados, por no hablar de las diferencias lingüísticas» (2004:158).

\section{HACIA UN NUEVO ENFOQUE DE LA COOPERACIÓN TERRITORIAL EN LA UNIÓN EURO- PEA. EL SIGNIFICADO DE LAS AGRUPACIONES EUROPEAS DE COOPERACIÓN TERRITO- RIAL}

\section{La progresiva asimilación de la necesidad de un instrumento comunitario aplicado a la cooperación territorial}

Aunque la tradición y la experiencia adquiridas hayan permitido alcanzar avances notorios en el conocimiento mutuo y en la realización de iniciativas de interés común, conviene reconocer también que la aplicación de INTERREG se ha decantado en la primera década del siglo XXI a favor de una reorientación de los instrumentos en los que hasta entonces se había apoyado la cooperación entre territorios de ámbito interestatal, ya que «ninguno de esos mecanismos resuelve a escala europea el problema de la puesta en marcha de la cooperación transfronteriza» (TICES, 2004:158). No sorprende, por tanto, que desde la propia Iniciativa Comunitaria se preconice la opinión favorable a crear «unas estructuras comunes para preparar los programas, hacer partícipes a las partes interesadas, seleccionar las operaciones, gestionarlo todo y coordinar y controlar la aplicación de los planes y, en su caso, los mecanismos conjuntos para la gestión de las medidas y operaciones» (Sobrido, 2004, 5).

Será, en fin, el argumento que de manera precisa defienda el Tercer Informe, donde se habla en concreto de «un nuevo instrumento jurídico, consistente en una estructura europea de cooperación». La justificación viene dada por la necesidad de que las instancias administrativas implicadas - Estados, Regiones, Municipios - «puedan resolver - tanto en el marco de los programas comunitarios como fuera de ellos - los problemas jurídicos y administrativos tradicionales que plantea la gestión de los programas y de los proyectos transfronterizos». El objetivo de esta figura consistirá en «transferir a esta nueva estructura jurídica la capacidad necesaria para llevar a cabo actividades de cooperación en representación de las autoridades públicas. (TICES, 2004:20).

Evidentemente no es posible entender este planteamiento a favor de la corrección de las disfunciones surgidas en un marco proclive a la generación de tensiones jurídico-administrativas sin valorar al propio tiempo la relevancia otorgada al conjunto de la cooperación territorial - en sus modalidades de transfronteriza, transnacional e interregional- como uno de los pilares esenciales de la Política de Cohesión diseñada para el periodo 20072013. En la delimitación de los tres grandes Objetivos que la identifican, el centrado en la Cooperación Territorial comparte posición estratégica con el de Convergencia y el de Competitividad Regional y Empleo. No en vano la relevancia otorgada al enfoque de carácter cooperativo aparece ya claramente ratificada en la comunicación de la Comisión, de 5 de julio de 2005, sobre «Política de cohesión en apoyo del crecimiento y el empleo: directrices 
estratégicas comunitarias 2007-2013» con el consiguiente reflejo financiero que emana del acuerdo interinstitucional correspondiente. Y será además el fundamento en el que se apoye la aprobación de la pieza esencial concebida para subsanar las limitaciones de las estructuras de cooperación precedentes, del mismo modo que cobra fuerza la propia reflexión suscitada desde ESPON (European Spatial Planning Observation Network), cuando alude a que la «integración de las áreas fronterizas puede impulsar la formación de regiones funcionales» (ESPON, 2006:6).

\section{La Agrupación Europea de Cooperación Territorial: un instrumento con objetivos y procedi- mientos bien definidos, y un buen nivel de aceptación}

No cabe duda que el Reglamento (CE) n ${ }^{\circ}$ 1082/2006 del Parlamento Europeo y del Consejo, de 5 de julio de 2006, por el que se crea la figura de la Agrupación Europea de Cooperación Territorial $(\mathrm{AECT})^{7}$, representa un hito crucial tanto en la trayectoria de la política de cohesión practicada por la Unión Europea como en el desarrollo de los procedimientos adaptados a las exigencias de la ordenación del territorio y el desarrollo territorial arropadas en el amplio campo de posibilidades que permite la cooperación descentralizada. En realidad se trata de una decisión sustentada en el planteamiento que desde 2004 defienden conjuntamente la Unión Europea y el Consejo de Europa en el sentido de introducir «un instrumento conjunto de cooperación transeuropea» comprensivo de todas las modalidades de cooperación entre las autoridades y comunidades locales de ambos escenarios (Council of Europe, 2006:25).

A partir de su entrada en vigor el 1 de enero de 2007 es posible disponer de un instrumento de Derecho comunitario dotado de personalidad y capacidad jurídica, específicamente concebido para el fomento de la cooperación territorial e implicando a miembros situados en el territorio de al menos dos Estados miembros (Beltrán, 2010: 59). Objetivos que, a través de las AECT - que actúan en nombre y por cuenta de sus miembros con la capacidad jurídica que las legislaciones nacionales reconocen a las personas jurídicas - pueden verse satisfechos merced a las posibilidades permitidas para la aplicación de programas y proyectos cofinanciados por la Comunidad ${ }^{8}$ o bien por iniciativa de los Estados y sus autoridades regionales y locales, con o sin contribución financiera de aquélla. Asimismo se faculta para formar parte de ella, y con carácter facultativo, a los organismos de Derecho público 9 .

Con razón se ha señalado que el Reglamento que crea las AECT tiene un carácter «atípico» en la medida en que, a diferencia de lo que sucede con los Reglamentos, y de confor-

7 Diario Oficial L 210 de 31.7.2006

8 Conforme al Reglamentos 1080/2006 relativo al Fondo Europeo de Desarrollo Regional, que a su vez deroga el Reglamento 1783/1999 y el 1083/2006. por el que se establecen las disposiciones generales relativas al Fondo Europeo de Desarrollo Regional, al Fondo Social Europeo y al Fondo de Cohesión y la derogación del $1260 / 1999$.

9 Esta figura será posteriormente recogida y respaldada por los Estados miembros del Consejo de Europa al suscribir en Utrecht el 16 de noviembre de 2009 el «Protocolo n 3 a la Convención-marco europea sobre la cooperación transfronteriza de las colectividades o autoridades territoriales relativo a las Agrupaciones eurorregionales de Cooperación». Se apoyará en el plan de acción adoptado en la Tercera Cumbre de Jefes de Estados y de Gobierno del Consejo de Europa, celebrada en Varsovia el 16 y 17 de mayo de 2005, donde se subraya «el desarrollo de la cooperación transfronteriza como una necesidad» 
midad con lo establecido en el Art. 249 del Tratado CE, donde se señala que «será obligatorio en todos sus elementos y directamente aplicable en cada Estado miembro», el que nos ocupa remite su cumplimiento a la adopción por parte de los Estados «de las disposiciones adecuadas para garantizar la aplicación efectiva del Reglamento en cuestión» (Embid y Fernández de Casadevante, 2009: 78). Así se explica, como si de una Directiva se tratase, el alcance de su trasposición al ordenamiento español mediante R.D. 37/2008, de 18 de enero (BOE 19 de enero de 2008) por el que se adoptan las medidas necesarias para la aplicación efectiva del Reglamento ${ }^{10}$.

Entre sus disposiciones básicas, que lógicamente ejercen un papel estructurante de su capacidad operativa, procede resaltar la importancia concedida a la formalización de un Convenio entre las partes implicadas que adecuarán sus relaciones y directrices estratégicas al régimen estatutario que desarrolle los propios objetivos contemplados en aquél, al tiempo que promueve la dotación de órganos de gobierno propios y la fijación de normas relativas al presupuesto y al ejercicio de su responsabilidad financiera. De ahí que tanto las particularidades que han de regular el funcionamiento de la Agrupación y su ámbito espacial de referencia como los procedimientos aplicados a la adopción de los acuerdos de cooperación y la toma de decisiones han de aparecer claramente delimitados en ambos documentos básicos, que aseguran y garantizan así su personalidad jurídica y su homologación plena en el ámbito comunitario.

En este sentido, resulta pertinente la puntualización realizada por Embid y Fernández de Casadevante (2009:200) a propósito de la relación de correspondencia que, con criterios de coherencia y afinidad de objetivos, pudiera plantearse entre las finalidades genéricamente previstas en el Art. 7 del Reglamento que crea las AECT — «facilitación y promoción de la cooperación territorial para fortalecer la cohesión económica y social» (art. 7.2) - y los objetivos, más específicos, que ya aparecían contemplados para los Convenios de Cooperación en el Art. 5 del Tratado de Valencia suscrito en 2002 entre España y Portugal. No en vano son finalidades coherentes con los principios a los que se acomoda el sentido mismo de la cooperación transfronteriza, susceptibles de estructurarse en función de ejes de actuación esenciales y de orientar, por tanto, con plena racionalidad la trayectoria de las Agrupaciones. $\mathrm{Y}$ es que no cabe duda que los límites en que han de desenvolverse los vínculos creados a partir de ellas quedan clarificados por los siguientes fines de interés común:

- «concertación de iniciativas y adopción de decisiones

- promoción de estudios, planes, programas y proyectos, especialmente los que sean susceptibles de cofinanciación estatal, comunitaria o internacional

- realización de proyectos de inversión, gestión de infraestructuras y equipamientos, y prestación de servicios de interés público.

- promoción de formas de relación entre agentes, estructuras y entidades públicas y privadas que puedan contribuir al desarrollo de los territorios fronterizos respectivos»

$\mathrm{Si}$, a modo de ejemplo expresivo, es fácil percibir cómo en el ámbito de las relaciones hispano-portuguesas la creación de una AECT posibilita avances en sintonía con la línea contemplada en los Tratados bilaterales suscritos con anterioridad a la entrada en vigor de la Agrupación, no sorprende que en el panorama general de la cooperación territorial en la

10 En Portugal se llevará a cabo con anterioridad, mediante Decreto-Lei 376/2007, de 8 de noviembre. 
Unión Europea la puesta en marcha de esta figura jurídica haya merecido una atención nada desdeñable por parte de las distintas administraciones públicas.

Cuadro 2

AGRUPACIONES EUROPEAS DE COOPERACIÓN TERRITORIALAPROBADAS (2010)

\begin{tabular}{|l|r|r|}
\hline \multicolumn{1}{|c|}{ AECT } & $\begin{array}{r}\text { Creación } \\
\text { (mes/año) }\end{array}$ & Estados implicados \\
\hline Eurometrópolis Lille-Kortrijk-Tournai & 1.2008 & Bélgica y Francia \\
\hline Ister-Granum & 9.2008 & Hungría y Eslovaquia \\
\hline Galicia-Norte de Portugal & 10.2008 & España y Portugal \\
\hline Anfictionía & 12.2008 & $\begin{array}{r}\text { Grecia, Chipre. Italia y } \\
\text { Francia }\end{array}$ \\
\hline Karst-Bodva & 2.2009 & Hungría y Eslovaquia \\
\hline Duero-Douro & 3.2009 & España y Portugal \\
\hline Flandes Occidental/ Flandes-Dunkerque-Costa de Ópalo & 3.2009 & Bélgica y Francia \\
\hline Guadiana Central & 4.2009 & España y Portugal \\
\hline Archimed & 7.2009 & España, Italia y Chipre \\
\hline Eurorregión Pirineos-Mediterráneo & 8.2009 & España y Francia \\
\hline Estrasburgo-Ortenau & 2.2010 & Francia y Alemania \\
\hline Hospital de la Cerdanya & 4.2010 & España y Francia \\
\hline ZASNET & 3.2010 & España y Portugal \\
\hline Programa Gran Región & 4.2010 & Francia, Alemania, \\
& & Bélgica y Luxemburgo \\
\hline UTTS & 4.2010 & Hungría y Eslovaquia \\
\hline Eurodistrict Saar-Moselle & 5.2010 & Alemania y Francia \\
\hline
\end{tabular}

Fuente: Comité de las Regiones. 2010.

El cuadro 2 refleja el sentido de una tendencia favorable a la aceptación como marco jurídico de referencia comunitaria. Apenas tres años después de la entrada en vigor del Reglamento, y teniendo en cuenta el lapso provocado por los plazos de trasposición a los respectivos ordenamientos estatales, el panorama se enriquece con la existencia de quince $\mathrm{AECT}$, a las que habría que sumar la perspectiva abierta por las que se hallan en proceso de preparación a 1 de octubre de $2010^{11}$.

11 Son las siguientes: Eurorregión Tirol-Alto Adagio-Trentino (Italia y Austria), Tritia (Eslovaquia, República Checa y Polonia), Eurorregión Ulm-Viena-Budapest (Alemania, Hungría y Austria), Eurorregión Alpes-Mediterráneo (Italia y Francia), Territorio de los Municipios (Gorizia, Nova Gorica y Sempeter-Vrtojba) (Italia y Eslovenia), Euranest (Bélgica, Francia, Italia y Suiza), Navegación común del Danubio (Bulgaria y Rumania), Eurorregión Mosa-Rhin (Bélgica y Alemania), Aglomeración Alzette-Belval (Francia y Luxemburgo), Eurorregión Neisse-Nisa 
Aunque es evidente que cada una de estas iniciativas presenta matices que revelan tanto las circunstancias específicas que las motivan como el sesgo que los poderes públicos otorgan a sus políticas de cooperación transnacional, podemos señalar que, en esencia, obedecen a dos factores coincidentes en la mayoría de los casos: de una parte, es posible apreciar, a través de ellas, la solución de continuidad que de este modo se establece respecto a la experiencia previa favorecida por los vínculos fraguados al amparo de la iniciativa INTERREG, que trata de ser valorizada aprovechando las posibilidades del nuevo contexto, si bien el ámbito de relaciones se amplia espacialmente más allá del estricto escenario fronterizo; y, de otra, parece evidente la pertinencia generalizada de un propósito explícito a favor del aprovechamiento de las economías de escala territoriales que se generan mediante programa de cooperación en su mayoría muy abiertos y susceptibles, merced a la coherencia permitida por este instrumento comunitario, de ser tenidos en cuenta con especial atención en virtud de su sintonía con los objetivos y procedimientos inherentes al propio desarrollo de la Agrupación como demostración de las posibilidades derivadas de los modelos de gobernanza multivel.

No de otro modo podría entenderse el respaldo otorgado por el Parlamento Europeo, cuando en una Propuesta de Resolución «insta a los Estados miembros que todavía no lo hayan hecho a que adopten cuanto antes las disposiciones necesarias para crear agrupaciones europeas de cooperación territorial (AECT); recomienda que la Comisión promueva el intercambio de información entre las AECT ya creadas y aquéllas que se encuentran en proceso de creación en el marco de los actuales programas y felicita al Comité de las Regiones por la calidad de su trabajo sobre las AECT y pide que sus instrumentos disponibles, en particular la Plataforma de Seguimiento de Lisboa y su Red de Control de la Subsidiariedad, se utilicen para estimular el intercambio de mejores prácticas entre las regiones y los Estados miembros» ${ }^{12}$.

\section{EL ESPACIO DEL DUERO-DOURO: UN TERRITORIO ABIERTO A LA EXPERIMENTACIÓN DE POLÍTICAS DE COOPERACIÓN INTERMUNICIPAL CON VOLUNTAD INNOVADORA}

De los factores y rasgos señalados participa plenamente el proyecto de cooperación intermunicipal vertebrado en torno a la AECT Duero-Douro. Tanto en la justificación de su origen como en la delimitación de los objetivos que la inspiran no hay fractura alguna respecto a lo que ha sido la defensa de una trayectoria de relaciones fuertemente enraizada en el tiempo. No sorprende, en efecto, que cronológicamente su puesta en marcha figure entre las primeras iniciativas aprobadas con implicación española. Nacida en el mes de marzo de 2009, sucede en el tiempo a la primera de todas, la de protagonismo más previsible y lógico, la formada por Galicia y la Región Norte de Portugal, dos espacios tan estrechamente imbricados que

\footnotetext{
(Alemania, Polonia y República Checa), Donauhanse (Ciudades ribereñas del Danubio a lo largo de diez Estados), Alpi Maritime-Mercantour (Francia e Italia), Alpen-Adria (Italia, Austria, Eslovenia, Hungría y Croacia), Eurodistrito Oderland Nadodrze (Alemania y Polonia), Eurociudad Chaves-Verín (Portugal y España), Eurodistrito Saar-Moselle (Alemania y Francia), Europaregion Donau-Moldau (Alemania y República Checa), Bratislava - Niederösterreich (Eslovaquia y Austria), Eurorregión Corridor VIII (Italia, Bulgaria y Albania) y Ung-Tisza-Túr-Sajó (Hungría, Eslovaquia, Rumania y Ucrania). Fuente: Comisión Europea. Política Regional- Inforegio.

12 Propuesta de Resolución del Parlamento Europeo (2009/2231 (INI) sobre buena gobernanza en el ámbito de la política regional de la UE. La Resolución fue aprobada en Comisión el 29 de septiembre de 2010.
} 
hubiera llamado la atención el que no hubiera ocurrido de ese modo. En cualquier caso, la frontera hispano-portuguesa, la «raya» en su acepción más asumida, reafirma así su condición de espacio decididamente proclive a la cooperación transnacional, considerada desde los primeros momentos de la integración en la Comunidad Europea como una necesidad imperiosa y a la par abierta a la posibilidad de puesta en práctica de nuevas pautas y modelos de gestión público-privada (Moura, 2005, 16).

De ahí que el salto cualitativo que supone la entrada en vigor de una AECT, con todo lo que ello representa respecto a la corresponsabilidad de las partes implicadas, no pueda entenderse al margen de la voluntad de avanzar en la consolidación de unos vínculos entendidos como la única garantía capaz de hacer frente a las dificultades estructurales cuya tipología y gravedad forman parte de las clarividencias omnipresentes y más asumidas en las sociedades «rayanas» y que no han cesado de ratificarse al amparo de los avances conseguidos en el conocimiento del territorio, tanto en su interpretación más crítica como en la que pondera objetivamente la dimensión de sus potencialidades, directamente proporcionales con las perspectivas abiertas en el seno de un entramado eficiente, o susceptible de serlo, de relaciones, estrategias y riesgos compartidos.

\section{De la objetividad de los diagnósticos y la clarificación de estrategias coordinadas al desa- rrollo de la capacidad asociativa local}

Si el caudal de información de que se dispone - tan relevante como la propia calidad de los diagnósticos referidos a la realidad espacial considerada (Cabero, 1993; López Trigal, $1993)^{13}$ - proporciona una sólida base de partida a la hora de diseñar posibles estrategias de desarrollo, no es menor la convicción sobre la importancia que desempeña el mantenimiento de una cultura activa de la cooperación entre territorios a escala local, merced al balance extraído de las experiencias respaldadas por la iniciativa INTERREG. Un balance caracterizado por algunos logros y no pocas frustraciones, producto inevitable de ese juego de ambivalencias, e incluso de contradicciones, que ha sido objeto de estudio en todas sus facetas, resultados, posibilidades y limitaciones (Carrera, 2000, 2002; Manero et al., 2000), hasta el punto de que pocas incertidumbres existen ya sobre los factores que impulsan en unos caos y condicionan en otros el cumplimiento de los objetivos inherentes a la puesta en marcha de programas de cooperación comúnmente ambiciosos en sus planteamientos iniciales. En cualquier caso, sobre la base de la experiencia acumulada parece evidente que los efectos provocados por la cooperación se caracterizan por presentar un sesgo muy marcado a favor de las ayudas destinadas a la financiación de equipamientos e infraestructuras en general mientras son claramente insuficientes las aportaciones financieras privadas, lo que demuestra el escaso nivel de riesgo asumido por este sector y, por ende, una tendencia a la infrautilización de las ayudas ante la escasez de proyectos transfronterizos susceptibles de verse respaldados por ellas (Moltó, 2000, 90).

13 Bastaría con comprobarlo a través del importante fondo de investigación y documental existente en los archivos y la Biblioteca de la Fundación Rei Afonso Henriques, con sede en la ciudad de Zamora. Vid. http://www. frah.es/index_ES.asp 
En un ámbito donde los diagnósticos sobre los problemas existentes se muestran tan obvios como la toma de conciencia proclive al mantenimiento de los principios en los que se apoya la voluntad de cooperación no resulta difícil entender la pronta sintonía con las perspectivas favorables a que pudiera dar lugar la puesta en marcha de una Agrupación Europea de Cooperación Territorial, cuyo reconocimiento no es ajeno a las motivaciones y argumentos asumidos por un sector importante de la sociedad local. Sin duda, en principio, desempeña un papel destacado, como factor clarificador de estrategias a seguir, el conjunto de reflexiones recogidas y sistematizadas en el Programa Operativo de Cooperación Transfronteriza España-Portugal (2007-2013).

A través de las reuniones celebradas en las distintas áreas de cooperación con participación directa de las Comunidades Autónomas españolas y las Comisiones de Coordinación de las regiones portuguesas, cuyo punto de partida tuvo lugar en la reunión sobre programación transfronteriza celebrada en Vila Viçosa en enero de 2006, se asiste a un proceso de clarificación de objetivos y ordenación de estrategias, que toman como base de partida la experiencia previa y los vínculos ya configurados con la intención de adecuarlos a los nuevos parámetros que impone la reforma de la Política de Cohesión iniciada a partir de 2007.

Tanto en el caso del Área de Cooperación que Castilla y León configura con la Región Norte como en el que relaciona aquélla con la Región Centro las prioridades establecidas se muestran coherentes con la pretensión de estimular la dinamización de estos espacios en función de cuatro objetivos esenciales, entre los que se trata de establecer sinergias favorecedoras para el desarrollo integral del territorio, a saber: fomento de la capacidad de iniciativa empresarial, protección ambiental y de los recursos patrimoniales, aprovechamiento de los efectos inducidos por la mejora de las infraestructuras y perfeccionamiento de las estructuras de cooperación e integración social. Por tanto, si las directrices planteadas por el Programa Operativo Transfronterizo introducen un marco de referencia necesario para la determinación de las estrategias a seguir, su virtualidad hubiera sido muy reducida de no contar con la voluntad explícita de participación emanada de las corporaciones locales, y de los liderazgos correspondientes, que en este proceso ejercen un protagonismo muy destacado. En otras palabras, la iniciativa de los municipios resulta clave para comprender el nivel de aceptación alcanzado por esta opción cooperativa de origen comunitario, lo que constituye una demostración fehaciente de las posibilidades inherentes a las diferentes formas y pautas de actuación de que es susceptible el asociacionismo municipal (Manero, 1997: 52).

Aunque existe una significativa tradición previa de cooperación intermunicipal, manifestada en los numerosos convenios de cooperación transfronteriza acordados desde los años noventa, es evidente, tal y como he podido comprobar in situ, que la sensibilidad a favor del fortalecimiento de espacios de encuentro y relación en estas áreas ha sido mucho más activa por parte de las instancias, públicas y privadas, españolas, seguramente debido a una preocupación mayor desde su perspectiva sobre las dificultades estructurales que entorpecen el desarrollo en estos espacios de borde, que en la percepción portuguesa son más bien entendidas como áreas «da interioridade», esto es, como ámbitos alejados y diferenciados de las áreas, dinámicas y expansivas, del litoral.

Sólo así cabe valorar el significado de alguno de los precedentes que en la vertiente española han conducido a la creación de la Agrupación. Entre ellos atención especial merece la Asociación de Municipios de la Raya del Duero, impulsada por la Fundación Encuentro 
y la Fundación Iberdrola, y en la que desde el primer momento mantuvo un protagonismo destacado Don José María Martín Patino, presidente de la primera y artífice de algunos de los principales proyectos de desarrollo (educativos, culturales y tecnológicos), que han actuado como factores de motivación de numerosos alcaldes y empresarios del espacio estudiado. Con independencia de los resultados conseguidos, obviamente mediatizados por su limitado horizonte de vigencia, no cabe duda de que la idea materializada en la reunión celebrada en la localidad salmantina de Villarino de los Aires los días 11 y 12 de noviembre de 2004 supuso un paso decisivo ya que en ella cobró entidad el acuerdo unánime de crear una Asociación de Municipios «para la mutua colaboración y el desarrollo local».

La propuesta cristalizaría finalmente en la firma del Acta Fundacional de la Asociación de Municipios para la Cooperación y el Desarrollo Local el 21 de enero de 2005, en la que inicialmente se integraron veintisiete Ayuntamientos, entre los que se pretendía establecer vínculos de relación permanente como partes integrantes de una red, en la que cada uno de ellos quedaría identificado como un «centro de cooperación al desarrollo local». Los testimonios recibidos revelan que la iniciativa contó con un amplio respaldo por parte de los municipios implicados desde la puesta en marcha de la Asociación, lo que no hacia sino ratificar el deseo de anudar formas diversas de colaboración, que cristalizarían en una red muy abierta en buena medida articulada en función de los objetivos contemplados en el Proyecto Raya Duero. Se trataba de un proyecto de carácter plurifuncional, planteado con una sólida fundamentación técnica, y capaz de operar como catalizador de la voluntad política de los alcaldes, a fin de implicarles activamente en la mejora del conocimiento de la realidad del área y en el impulso de la capacidad de iniciativa empresarial. La idea aparece impregnada desde sus inicios de un propósito que habría de suscitar gran interés, ante la posibilidad de convertir a parte de los Ayuntamientos en Centros de Cooperación para el Desarrollo Local (CODEL), a modo de espacios de encuentro y relación para la puesta en común de experiencias educativas, culturales y de servicios de interés compartido.

Los esfuerzos realizados por los promotores de la iniciativa, y particularmente por los representantes de la Fundación Encuentro, fueron esenciales en la trayectoria de esta experiencia, que contó con el apoyo de la Junta de Castilla y León y con colaboraciones empresariales relevantes (Iberdrola, Hewlett Packard, IBM) que aportaron la ayuda económica y la infraestructura tecnológica necesaria para seguir manteniendo el nivel de motivación con que fue impulsado el Proyecto y la Asociación que le proporcionó estructura organizativa y continuidad en el tiempo. No en vano se ha apuntado que ello se debió en buena medida a la percepción positiva que producía la superación de las sensaciones de aislamiento y marginalidad que históricamente han condicionado a las sociedades rayanas.

\section{El proceso hacia la AECT Duero-Douro: un camino inexorable. Estructura y posibilidades}

Hay que recurrir a esta experiencia previa para entender los pasos encaminados en la dirección que, finalmente, habrá de conducir a la formación de una Agrupación Europea de Cooperación Territorial. A través de las sucesivas Asambleas de la Asociación de Municipios se irá produciendo la incorporación de nuevos Ayuntamientos hasta alcanzar, tras la celebración de la IV Asamblea en noviembre de 2007, un total de 47, mayoritariamente de la provincia de Salamanca a los que se suman varios de la de Zamora. En conjunto se identifica 
con el ámbito de los «arribes» del Duero, lo que le confiere una personalidad geográfica bien marcada, que a su vez se fortalece tras la incorporación de la Asociación Vinduero-Vindouro, radicada en la localidad salmantina de Trabanca, y que desde el primer momento se reveló como una actuación muy decidida en el terreno de la acreditación turística del área sobre la base del prestigio que proporciona la producción vitivinícola y la serie de efectos inducidos sobre la sociedad, la economía y el territorio asociados a ella. Al propio tiempo, y desde la perspectiva de algunos ayuntamientos, se aborda la necesidad prolongar la cooperación transfronteriza desarrollada al amparo de un programa impulsado por la iniciativa comunitaria EQUAL, cuyos resultados se valoran como satisfactorios y necesitados de continuidad.

No sorprende, por tanto, que, finalizado ese programa y un mes después de celebrada la IV Asamblea de la Asociación de Municipios para la Cooperación y el Desarrollo, tuviera lugar el 27 de diciembre de 2007 en Trabanca una reunión en la que el presidente de la Fundación Encuentro, D. José María Martín Patino, en calidad de presidente de la Asociación, y el alcalde de Trabanca, D. José Luis Pascual, quien a su vez dirigía la Asociación Vinduero- Vindouro, presentaron a la mayoría de los alcaldes integrados en la primera y a varios presidentes de Cámaras Municipales portuguesas la propuesta de constituir una Agrupación Europea de Cooperación Territorial (AECT), de las que hasta entonces sólo existía en España la formada por Galicia y la Región Norte de Portugal.

La aceptación de la propuesta conduciría, finalmente, al acto público de presentación oficial de la AECT Duero-Douro en aguas internacionales, junto a Miranda do Douro, el 7 de marzo de 2009, como paso previo a la celebración, una semana después (el 14 de marzo) y en Trabanca, de la Asamblea Constitutiva, donde se llevó a cabo la ratificación del Convenio, la aprobación de los Estatutos y la elección de los órganos directivos ${ }^{14}$. Su creación no supuso el fin de la Asociación auspiciada por la Fundación Encuentro ni el Proyecto Raya Duero ni la Red de Centros CODEL, y que tanto contribuyeron al nacimiento de la Agrupación y a la vertebración inicial de los municipios que la acabarían integrando. Toda esa estructura continuó colaborando activamente con ella, fiel al compromiso de «trabajar por la cohesión económica y social» de las zonas fronterizas» y con el convencimiento de estar «ante una ocasión sin precedentes históricos para actuar en régimen de cofinanciación con la Unión Europea, a la transformación económica, social y cultural de toda la zona fronteriza de Zamora y Salamanca. El recorrido es largo y las esperanzas de fruto cierto no pueden ser más seguras» ${ }^{15}$.

La iniciativa, que finalmente será reconocida en el Diario Oficial de la Unión Europea de 16 de junio de 2009, cristaliza en una red de notable envergadura administrativa y espacial. En ella se integran 165 corporaciones locales, de las que 96 pertenecen a las provincias de Salamanca y Zamora, y 69 son autarquías locales portuguesas (concelhos, freguesías y Aso-

14 La Presidencia sería desempeñada por Gustavo de Sousa, presidente de la Cámara de Vila Nova de Foz Coa, la Vicepresidencia por José María Martín Patino, presidente de la Fundación Encuentro, y la Dirección General por José Luis Pascual Criado, alcalde de Trabanca. Sin embargo, a mediados de diciembre de 2010, el Sr. Martín Patino presentó su dimisión, por razones que se han revelado muy controvertidas en su tratamiento mediático. Es una información que me ha sido proporcionada por el Dr. Luis Alfonso Hortelano Mínguez, profesor de la Universidad de Salamanca, a quien agradezco su deferencia.

15 http://www.fund-encuentro.org/raya/asociacion/aect $2 . \mathrm{htm}$. 
ciaciones de freguesías), de las regiones de Tras-os-Montes, Douro y Beira Interior Norte ${ }^{16}$. A ellos se suma la Asociación de Municipios para la Cooperación y el Desarrollo Local y el Organismo Autónomo D-Arribes ${ }^{17}$ al tiempo que cuenta con la presencia de la Universidad de Salamanca y del Instituto Politécnico de Bragança.

Las características del área, que abarca cerca de $9.000 \mathrm{Km}^{2}$ y en la que se residen 120.000 personas, se identifican claramente con las propias de un espacio marcadamente periférico, eminentemente rural, en el que predominan núcleos de población con muy débil capacidad demográfica, ya que en sus dos tercios no alcanzan los 200 habitantes. Se trata además de un ámbito de gran calidad ambiental. La mayor parte del territorio a ambos lados de la «raya» posee el rango de espacio natural protegido, con particularidades ecológicas de un extraordinario valor. La existencia de una trama de cabeceras comarcales con tendencia mayoritaria al estancamiento e incluso regresión poblacional introduce un leve contrapeso a la desvitalización natural del conjunto, no obstante los síntomas y manifestaciones que de forma puntual revelan decididos esfuerzos encaminados a contrarrestar una tendencia declinante que es asumida como un desafío a afrontar con la mirada puesta en las perspectivas que derivan de las actuaciones susceptibles de auspiciadas por la Política de Cohesión de la Unión Europea, entendida como una salvaguarda indispensable.

Tratándose, pues, de un área suficientemente conocida y estudiada desde el punto de vista geográfico, interesa sobre todo valorar el alcance de la figura puesta en práctica y el sentido de las orientaciones estratégicas que la definen en un proceso cuyas posibilidades efectivas sólo pueden ser debidamente valoradas a medio y largo plazo. La lectura del Convenio y de los Estatutos proporciona argumentación suficiente para entender el margen de perspectivas creado y el nivel de compromiso asumido por las unidades administrativas que integran la Agrupación. En principio, no son pocos los riesgos que se plantean ante una estructura de cooperación tan atomizada y dispersa, en la que al tiempo abundan los municipios con escasa o nula experiencia en el establecimiento de vínculos orientados a ese fin.

La propia ordenación estatutaria, sustentada sobre tres pilares básicos - la Asamblea General, el Consejo de Coordinación y los Consejos Sectoriales ${ }^{18}-$, define un modelo organizativo en el que a la participación de los miembros se concede un papel esencial al tiempo

16 En esta relación se incluyen las entidades que figuran registradas en los textos que oficialmente formalizan el nacimiento y la composición de la Agrupación, es decir, la Orden APU/544/2009, de 11 de Febrero, «por la que se autoriza la participación de determinados municipios de las provincias de Salamanca y Zamora en la Agrupación Europea de Cooperación Territorial «Duero-Douro AECT» (BOE de 7 de marzo de 2009) y en la Resolución de 31 de marzo de 2009, de la Secretaría General Técnica del Ministerio de Asuntos Exteriores y Cooperación, «por la que se da publicidad a la inscripción de los estatutos» (BOE de 21de abril de 2009. Se adopta la relación originaria, que además permite precisar claramente las características y magnitud del espacio afectado y con independencia de las modificaciones producidas entre los miembros de la Agrupación por ingresos y abandonos de municipios, ya que en esencia estos movimientos no alteran sustancialmente la dimensión territorial del ámbito de cooperación ni, de momento, la pluralidad de núcleos que la integran.

17 El Organismo Autónomo D-Arribes es una entidad empresarial pública creada por el Ayuntamiento de Trabanca para garantizar el desarrollo socioeconómico del Parque Natural Arribes del Duero.

$18 \mathrm{Su}$ diversidad y sus denominaciones expresan claramente la pluralidad de perspectivas de acción hacia las que, en principio, se orienta la AECT. Son los siguientes: Igualdad de Oportunidades, Desarrollo Económico, Investigación, Innovación y Desarrollo; Desarrollo local, Nuevas Tecnologías, Educación, Formación y Empleo; Medio Ambiente, Desarrollo Sostenible, Agricultura y Ganadería; Turismo, Cultura, Patrimonio, Deporte, Ocio y Tiempo Libre; Administración Local, Transportes y Comunicaciones; y Sanidad, Servicios Sociales y Acción Social. 
Figura 1

MUNICIPIOS, CONCELHOS, FREGUESÍAS E INSTITUCIONES PRESENTES EN EL ACTO DE CONSTITUCIÓN DE LA AECT DUERO-DOURO

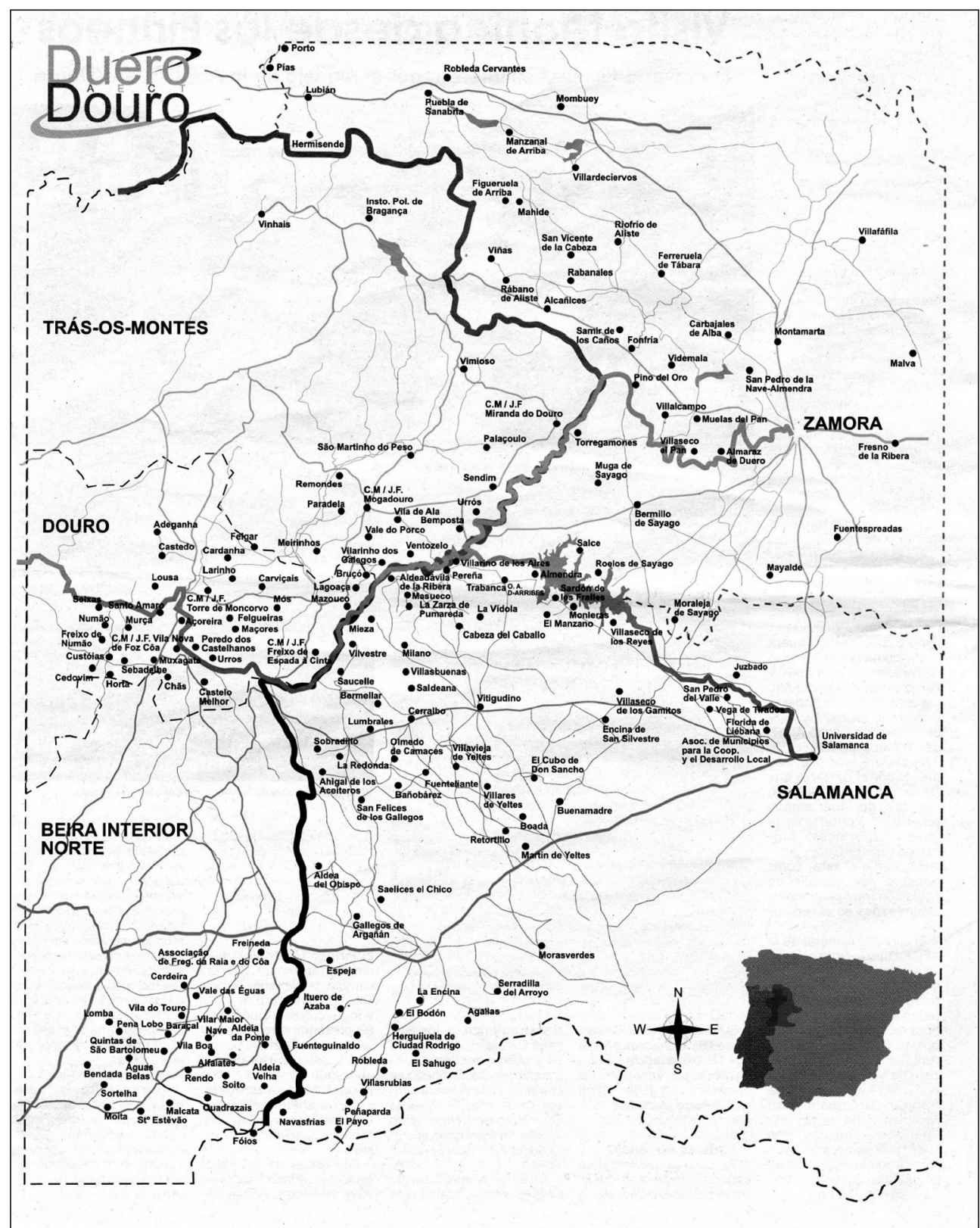

Fuente: AECT Duero-Douro. 
que conlleva la asunción de responsabilidades sólo entendibles en el marco de una progresiva asimilación de las ventajas inherentes a la cultura de la cooperación territorial, con todas sus ventajas, riesgos e incertidumbres. Por su parte, la expresión, a través del Convenio, de una voluntad de avanzar en esta dirección, con el objetivo de incidir positivamente en la transformación ordenada y coordinada del territorio, se muestra explícita en tres ideas que merecen ser destacadas.

De un lado, se trata de un instrumento operativamente concebido de manera muy abierta, susceptible de canalizar un amplio elenco de acciones en las que toda capacidad de iniciativa pueda tener cabida, con aplicación «en el ámbito territorial sometido a la respectiva jurisdicción competencial de los municipios miembros», por más que también quede facultada para «ejecutar sus cometidos en otros ámbitos territoriales siempre que sea delegataria de la autoridad competente». Es decir, el marco territorial, funcional y administrativamente municipalizado, puede expandirse de manera potencial favoreciendo un horizonte de cooperación territorial en todas sus perspectivas (transfronteriza, transnacional e interregional). A diferencia de otras AECT, la que nos ocupa tiene un carácter eminentemente multifuncional, aunque dentro de ella, y en sintonía con las líneas señaladas en el Art. 6 del Reglamento 1080/2006, se perciba un sesgo preferente hacia la búsqueda de compromisos que cristalicen en proyectos relacionados con el desarrollo rural apoyado en las ventajas comparativas de los recursos patrimoniales, en la conservación del medio ambiente y en las actividades con finalidad formativa, aprovechando los efectos generados por la infraestructura creada previamente en una parte de la red por la Asociación de Municipios.

De ahí «el especial interés» que, de otro lado, el Convenio concede al mantenimiento de las tareas de cooperación ya en fase de realización por parte de municipios dotados de experiencia previa, a los que se reconoce una autonomía en la gestión de los fondos, sin menoscabo de los mecanismos de control adoptados por parte de la Agrupación. Se trata así de aprovechar sus posibilidades, integrándolas en el funcionamiento global del entramado de relaciones ya configuradas o en vías de hacerlo, con el fin de generar sinergias y efectos de demostración importantes a la vez que necesarios para la armonización del conjunto.

Pues es evidente, por último, que al asegurar y potenciar de este modo las redes construidas, para abrirlas a la incorporación de quienes deseen formar parte de ellas o configurar otras nuevas, se garantiza un mayor margen de capacidad a la hora de ampliar el carácter sectorial de las actividades asumiendo los retos que el propio Convenio plantea para «la realización de obras públicas, la gestión común de equipamientos y la explotación de servicios de interés general que se instituyan como consecuencia de su funcionamiento, sea directamente por sus propios medios, sea con recurso a los medios disponibles al efecto por las administraciones miembros de la AECT, sea incluso a través de su licitación y contratación». Retos que igualmente puede afrontar al asumir, por delegación de las autoridades responsables del Programa Operativo, los subprogramas o iniciativas susceptibles de llevarse a cabo por la AECT, en cumplimiento de lo que al respecto señala el propio Reglamento del FEDER en el que se encuadra.

Definido claramente, el esquema de funcionamiento en el que han de apoyarse las actividades que aseguren los objetivos de cooperación que justifican la existencia de la Agrupación, la cuestión esencial estriba, como es obvio, en garantizar que eso ocurra y que las expectativas no se vean defraudadas. El panorama abierto tras la entrada en vigor de la 
Agrupación se traduce en un escenario de posibilidades aún por desarrollar y que obviamente dependerá de la capacidad de iniciativa de la red y del grado de asimilación y convencimiento de sus ventajas por parte de la sociedad afectada. No es aventurado pensar que el horizonte de realizaciones depende en buena medida de tres factores a tener en cuenta: el poder de movilización y eficacia organizativa para elaborar proyectos integradores e insertos en los programas comunitarios, la optimización de las estructuras de cooperación preexistentes y la competencia para diseñar líneas de acción debidamente acomodadas a las particularidades espaciales del área implicada.

Sucintamente cabe decir que el cumplimiento del primer requisito ya se ha puesto en evidencia a finales de 2009 cuando desde la Agrupación se planteó la toma en consideración de la segunda convocatoria del Programa de Cooperación Territorial Espacio Sudoeste Europeo (INTERREG IV B), lo que llevó a la elaboración de unas bases «para la participación de la ciudadanía de su territorio en la presentación de propuestas para ser elaboradas, definidas y desarrolladas de forma integral». La alusión que específicamente se hace sobre la idea de participación subraya el sentido mismo de la estrategia que se intenta llevar a cabo. Y del mismo modo, resulta ilustrativo el énfasis puesto en seguir aprovechando la experiencia construida al amparo de las sinergias, ya comprobadas, que pudieran derivarse del Proyecto Raya Duero, auspiciado por la Fundación Encuentro, impulsor de la Asociación de Municipios para el Desarrollo Local creada en 2004 y concebido desde sus orígenes como iniciativa de apoyo y colaboradora con cuantas actuaciones de cooperación intermunicipal emanen del propio territorio.

Son, en cualquier caso, plataformas de partida de cierta consistencia que ponen de relieve los avances dados ya en la dirección pretendida, y sobre las que poder sustentar propuestas que profundicen en ella. De ahí el significado que, como plan de actuación hacia el futuro, puedan tener las que, como ideas surgidas tras la entrada en vigor de la Agrupación, insisten en la pertinencia de acometerlas en función de las características espaciales que definen al ámbito de actuación. Es la finalidad con la que aparece planteada, entre las más relevantes, la creación de un Observatorio para la Promoción Cultural del eje Duero-Douro, con el apoyo del Ministerio de Cultura y la participación activa de la Asociación Juvenil «Las Arribes del Duero», y al que se le asigna la responsabilidad de llevar a cabo labores educativas, entre otras la destinada a la «Realización de inventarios digitales del patrimonio cultural», dirigida a jóvenes de uno y otro lado de la frontera. Como también merece ser reseñada en esta línea la Red Transfronteriza de Educación Intercultural Duero-Douro, la única que en Castilla y León forma parte en 2010 de las Asociaciones Comenius Regio, de estímulo a la cooperación regional en la enseñanza escolar y al intercambio de buenas prácticas educativas entre regiones y municipios. Y es que si la educación constituye en los momentos iniciales de la andadura de la AECT uno de sus principales emblemas, tampoco habría que desestimar la atención prestada, en coherencia con lo que suele ser habitual en el campo de la cooperación entre territorios, a los proyectos relacionados con el aprovechamiento de sus potencialidades turísticas o la conservación de sus valores ambientales.

De ahí la formalización de proyectos enmarcados en los programas y objetivos cuya sola mención permite reconocer el sentido de las acciones en curso. A modo de referencias ya plausibles, baste mencionar el denominado «Desarrollo Turístico de la Frontera», centrado en la identificación de recursos patrimoniales de gran valor como oferta cultural y de ocio, 
adscrito al Programa Operativo Transfronterizo, arropado por el FEDER; el «Sustainable Quality», pionero en España, para la puesta en marcha de una red de centros tecnológicos que permitan testificar la calidad del agua en los espacios protegidos de Arribes del Duero, Montesinho, Sierra de la Culebra y Lago de Sanabria; el «Proverte $I+D+i »$, de valorización de recursos endógenos y territoriales e incluido en la temática prioritaria «promoción de la $\mathrm{I}+\mathrm{D}+\mathrm{i}$ y mejora de la competitividad», presentado, como el anterior aunque en este caso ya admitido, al Programa SUDOE-Interreg IVB; el «Self Prevention» que se somete «como modelo de autogestión» a la financiación del Life Plus con la intención de expandir la ganadería caprina en el área, de suerte que, además de su utilidad económica, permita al tiempo aportar medidas de tratamiento del bosque capaz de minorar el riesgo de los incendios forestales que aquejan a la zona, lo que explica el apoyo manifestado por las administraciones portuguesas; $y$, finalmente en esta primera etapa, ha sido planteado el proyecto «Carretera Verde», que se identifica con un trazado viario de $400 \mathrm{kms}$. a gestionar dentro del Plan Estratégico de Infraestructuras de Transporte del Ministerio de Fomento, con el propósito de enlazar la autovía de Castilla, en su tramo salmantino, con la de las Rías Baixas, y favorecer así las posibilidades circulatorias y de articulación territorial en los municipios de Salamanca y Zamora ubicados a lo largo de su trazado.

\section{CONCLUSIONES}

Es evidente que la creación de las Agrupaciones Europeas de Cooperación Territorial como instrumento específicamente comunitario, acomodado a las respectivas normas estatales, supone un cambio estratégico y jurídico importante en la reordenación de las estructuras de cooperación entre territorios de la Unión Europea. Tratando de resolver las situaciones de inseguridad jurídica con que tradicionalmente se enfrentaban a la hora de armonizar estrategias entre espacios transnacionales para el logro de la cohesión económica, social y territorial - pues es evidente «que la cooperación transfronteriza o territorial no puede ser eficaz mientras los ordenamientos nacionales no cuenten con el marco jurídico necesario» (Embid y Fernández de Casadevante, 2009:253) - se abre así un interesante escenario de posibilidades para el despliegue de las iniciativas de desarrollo y riesgo compartido entre administraciones públicas, con particular relevancia en la escala local, que asume de este modo un protagonismo destacado. El papel de los municipios se halla, en efecto, ratificado por el notable margen de maniobra que se les concede a la hora de materializar directrices conjuntas que refuercen las relaciones de vecindad y aprovechen las ventajas inherentes a la proximidad territorial en los espacios transfronterizos. Una responsabilidad clave cuando se trata de afrontar los numerosos y relevantes desafíos a que obliga la política de cohesión en el marco de la Estrategia Europea 2020, así como los compromisos que deban asumirse en el contexto de la Plataforma de las AECT planteada en la Conferencia Europea de 28 de enero de 2011 e integrada en el Comité de las Regiones y concebida «como un espacio común de participación» de las Agrupaciones ya existentes o en preparación.

En este sentido, la puesta en marcha a comienzos de 2009 de la AECT Duero-Douro ilustra con expresividad el panorama de posibilidades, expectativas y riesgos que aquejan a un sector representativo de la frontera hispano-portuguesa, en el que la cooperación no mediatizada por la discontinuidad política que implica la «raya» tiende a ser aceptada como 
una opción estratégica esencial para acreditar el valor de los recursos y superar los problemas derivados de la situación periférica, la fragmentación funcional y la desvitalización demográfica y económica, siempre considerada como una de las principales servidumbres con que tropieza la ordenación del territorio en Castilla y León (Manero, 2004:235). Obviamente la satisfacción de los fines que la animan no será una tarea fácil ni cómoda, pues son aún numerosas las incógnitas que plantea la gestión y que sólo la aplicación práctica de la experiencia, con sus señales correctoras, permitirá resolver al compás de las modificaciones reglamentarias que puntualmente habrán de llevarse a cabo a fin de asegurar los niveles de eficacia pretendidos. Mas también está claro que de la calidad de la gobernanza aplicada a la gestión de la AECT, de su fortaleza para lograr el tránsito de una cooperación más informal a otra más formalizada e intensa, y de la voluntad de implicación desplegada por las autoridades locales, responsables del nivel de motivación de sus respectivos municipios y de su capacidad para alcanzar acuerdos por consenso, va a depender sin duda la consistencia de su capacidad de acción, apoyada en el amplísimo campo de actuación permitido por la cooperación intermunicipal, para afrontar los condicionamientos en que se encuentra un territorio estructuralmente crítico y por ello mismo necesitado de este tipo de políticas comunes apoyadas en la dimensión de escala territorial que neutralice las disfunciones asociadas al altísimo grado de atomización administrativa existente.

\section{BIBLIOGRAFÍA}

ANDERSON, J., O'DOWD, L. \& WILSON, T. (2003) (Eds.): New Borders of Changing Europe : Cross-Border Cooperation and Governance. London, Taylor \& Francis.

BELTRÁN, S. (2010): «Els organismes de cooperació territorial a Europa: una mirada cap al futur». Documents d'Anàlisi Geogràfica. 2010, vol. 56/1, 57-69.

CABERO, V. (1993): «Estudio regional de la zona fronteriza de Salamanca con Portugal» en Frontera y desarrollo. El programa transfronterizo de España y Portugal (Sánchez, F., dir.), 67-82.

CABERO, V. (2002): Iberismo y Cooperación: pasado y futuro de la Península Ibérica. Salamanca, Servicio de Publicaciones de la Universidad de Salamanca.

CARRERA, F.J. (2000) (Coord.): Cooperación transfronteriza: Castilla y León y Portugal, Madrid, Tecnos.

CARRERA, F.J. (2002): La cooperación transfronteriza hispano-portuguesa en 2001, Madrid, Tecnos.

CAVAILLÉ, F. (2009): «Quelle interdisciplinarité entre la géographie et le droit? Vers une géographie juridique?» en Géographie du Droit. Épistémologie, développement et perspectives (Forest, P. , dir.), 45-67.

CLOTET MIRÓ, M.A. (1992): La cooperación internacional de los municipios en el marco del Consejo de Europa, Madrid, Civitas.

COMISION EUROPEA (2004): Tercer Informe sobre la Cohesión Económica y Social. Bruselas, Comisión Europea.

COUNCIL OF EUROPE (2006): Practical Guide to Transfrontier Cooperation. http://www. espaces-transfrontaliers.org/en/studies/practical_guide_en.pdf 
EMBID, A. y FERNÁNDEZ DE CASADEVANTE, C. (2009): Las Agrupaciones Europeas de Cooperación Territorial. Consideraciones desde el Derecho Comunitario y el Derecho Español. Madrid, Iustel.

EUROPEAN SPATIAL PLANNING OBSERVATION NETWORK (2006): Territory matters for competitiveness and cohesion, Copenhague, ESPON Programme.

FOREST, P. (2009) (Dir.) : Géographie du droit. Épistémologie, développement et perspectives . Quebec, Presses Universitaires de Laval, Coll. Diké.

JACINTO, R. Y BENTO, V. (2005) (Coord): Territòrios e culturas ibéricas. Porto, Campo das Letras.

JACOMO, A.B. (2005): «Cultura de fronteira: um desafio à integração» en Territòrios $e$ culturas ibéricas. (Jacinto, R. y Bento, V.), 233-250.

LEVRAT, N. (2007) (Dir.) : Le Groupement européen de cooperation territoriale-GECT. Bruxelles, Comité des Regions.

LÓPEZ TRIGAL, L. (1993): «Estudio regional de la zona fronteriza de Zamora con Portugal» en Frontera y desarrollo. El programa transfronterizo de España y Portugal (Sánchez, F., dir), 45-54.

MANERO, F. (1997): «Significado funcional y territorial de las asociaciones de municipios», en I Seminario Iberoamericano sobre Mancomunidades Municipales, Valladolid, Junta de Castilla y León, 51-75.

MANERO, F. (2004): «Ordenación del territorio y desarrollo sostenible: ideas para una fundamentación de las políticas territoriales en Castilla y León», en Ordenación del Territorio y Desarrollo Sostenible (Millaruelo, J. y Orduña, E., dir.), 219-245.

MANERO, F. y PASTOR, L. (1986): «El impacto territorial de la integración de España en la CEE: problemas y estrategias de actuación en el marco de la Política Regional Comunitaria», en Actas del IV Coloquio Ibérico de Geografía. Coimbra, Instituto de Estudos Geográficos, 47-57.

MANERO, F., ANDRÉS, G. y MOLINA, I. (2000): Industria y Territorio en la Región Fluvial del Duero-Douro. Madrid, Sepes.

MERCHÁN, M.J. (2003): «El Tratado bilateral Hispano-Portugués sobre cooperación transfronteriza de 2002». Revista de Derecho Comunitario Europeo, $\mathrm{n}^{\circ}$ 15, 717-740.

MILlARUELO, J, y ORDUÑA, E. (Dir.): Ordenación del Territorio y Desarrollo Sostenible. Buenos Aires, Ciudad Argentina.

MOLTÓ, M. (2000): Los efectos de la Política Regional Comunitaria en la zona transfronteriza, en Cooperación transfronteriza: Castilla y León y Portugal, (Carrera, F., dir.), 83-93.

MOURA, T. (2005): «Novas institucionalidades e modelos de governação transfronteiriça» en Territòrios e culturas ibéricas. (Jacinto, R. y Bento, V.), 13-30.

O’DOWD, L. (2002): «The Changing Significance of European Borders», Regional and Federal Studies, 12 (4), 13-36.

RAFFESTIN, C. (1993): «Autour de la fonction sociale de la frontière», Espaces et Societés, 70-71, 157-164.

SÁNCHEZ, F. (1993) (Coord.): Frontera y desarrollo. El programa transfronterizo de España y Portugal. Salamanca, Instituto de Recursos Naturales y Agrobiología. 
SÁNCHEZ, F. y CABERO, V. (1994): La frontera hispano-portuguesa en el marco de la nueva Europa: la región fronteriza de Salamanca. Salamanca, Junta de Castilla y León y Comisión de las Comunidades Europeas.

SERRANO, C. y MONTORO, B. (2004), «Un nuevo horizonte para la política regional de la UE: el Tercer Informe de Cohesión», Boletín de Información Comercial Española, ${ }^{\circ}$ 2807, 3-14.

SOBRIDO, M. (2004): «El tratado hispano-portugués sobre la cooperación transfronteriza territorial». Revista Electrónica de Estudios Internacionales. http://www.reei.org/reei8/ SobridoPrieto_reei8_.pdf

WILSON, T. \& DONNAN, H. (Eds.) (1998): Border Identities : Nation and State at International Frontiers. Cambridge, Cambridge University Press 